\title{
Economic Bases of Formation and Development of Financial Engineering in Financial Innovation
}

\author{
A.A.Ajupov \\ Kazan Federal University, Institute of Management, Economics and Finance, \\ Email address: Ajdar.Ajupov@kpfu.ru \\ Artamonov A.B \\ Samara Academy of Humanities, Samara, 4430118, Russia \\ Kurilov K.U \\ Togliatti State University, Togliatti, 445667, Russia \\ Kurilova A.A. \\ Togliatti State University, Togliatti, 445667, Russia
}

Doi:10.5901/mjss.2014.v5n24p148

\begin{abstract}
Today the main spheres of society are developed mainly through the using of innovative technologies and constant updating of products. The result of active innovative activity of the economic subjects directed on the solution of different financial problems including the management all of increasing innovative risks became the prompt progress of financial engineering.m In turn, the process of designing innovative financial products created to reduce the various types of risks through instruments of financial engineering is characterized in economic science as a risk-engineering.
\end{abstract}

Keywords: innovation, life-cycle of innovation, innovation risk, financial ehgineering, innovative technologies, risk-engineering

\section{Introduction}

Currently not in doubt that the major spheres of society at the expense of developing innovative technologies. The path of constant updates of all activity in the market today is the most attractive. However, so far in the various branches of science, including in the economic, point of contention is the very definition of "innovation."According to the Assistant to the President of the Russian Federation Andrei Fursenko, "Innovation - it is not just something new. It is the application of knowledge to create new value, expressed in monetary terms." According to N. Ermilov, General Director of "Innovations of Leningrad Institutes and Enterprises", "Innovation - it is an innovation based on scientific research, which is implemented in the market. If innovation is sold in the market, so it is - an innovation. If not implemented - not innovation".

These definitions of innovation, as well, and some others found in scientific publications, are pragmatic enough and applied nature. In most publications, being based on the innovations in the field of scientific and technological progress, while the innovative processes in the economy remain outside review.

The dependence of the economy on science not only not diminished, but on the contrary, it becomes more and more obvious. In the U.S., where over 80 and especially 90 -ies of the last century showed very strong growth $(7.3 \%$ per year), the lowest in the history of the country's unemployment rate, record exports, and so on, there was a school economists argue that the economy based on knowledge, perhaps not subject to the laws of cyclicality, which determined the course of its development in the past. Innovations being introduced into society much faster than before. The development of innovation in the country determines the competitiveness in the international arena.

Innovation occurs when you use the results of research and development aimed at improving the process of production activities, economic, legal and social relations in the field of science, culture, education and other sectors of society. 


\section{Life-Cycle of Innovation}

The period of time from the inception of the idea, creation and dissemination of innovations and to use it is called lifecycle of innovation (Figure 1). Several distinct phases of the innovation cycle.

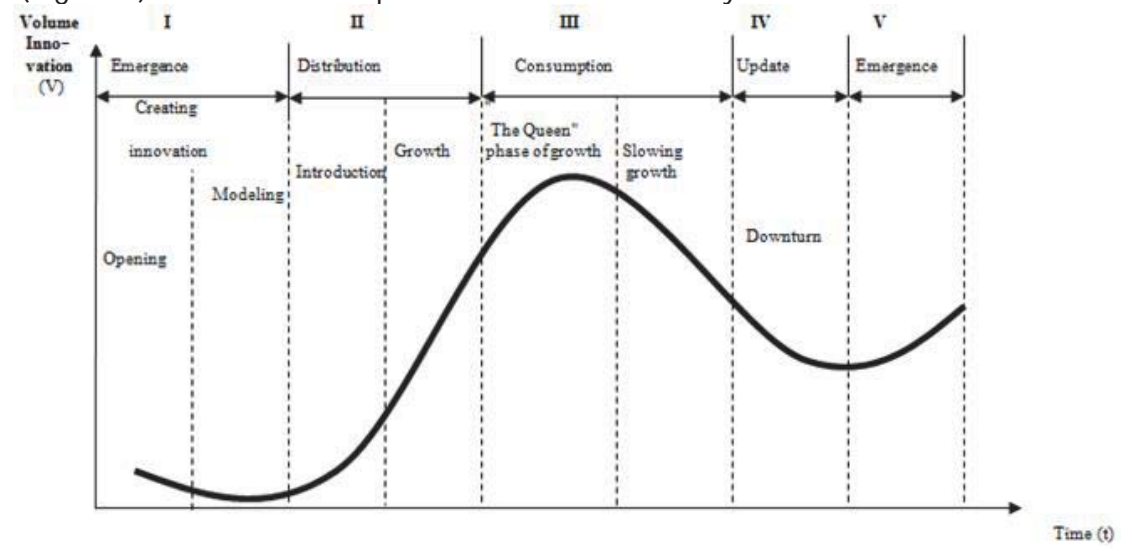

Figure 1. The life cycle of innovation

The first stage of the cycle is the occurrence or creation of innovation. It can be divided into two phases: the opening of innovation and styling. The scientists are not guided by practical motives, but from a desire to expand the understanding of the nature of things. They do not consider the results of their findings as a material for use in the production cycle. Due to the high cost of development and a fairly high level of risk financing, usually engaged state. Modeling involves the definition of feasibility and advisability of using the results of the opening in the practical sphere. Performed prototypes (models), the tests, the processing of test results. If the result is not a complete reflection of the real situation, the tests are repeated. The result is a prototype (model) of a product or idea, which is already possible to assess market prospects.

The second stage of the life cycle of innovation include the spread of innovation. This step is included in the innovation process, when the introduction of innovation is not limited to a single economic entity, and carried out at the level of the industry or the economic system as a whole. Here we select the phase of implementation and growth. The first is a "revision" model of a product or idea, that is, transformation model in a trade or industrial design. The second process is accompanied by a dynamic transformation in the tradition of innovation (Figure 2).

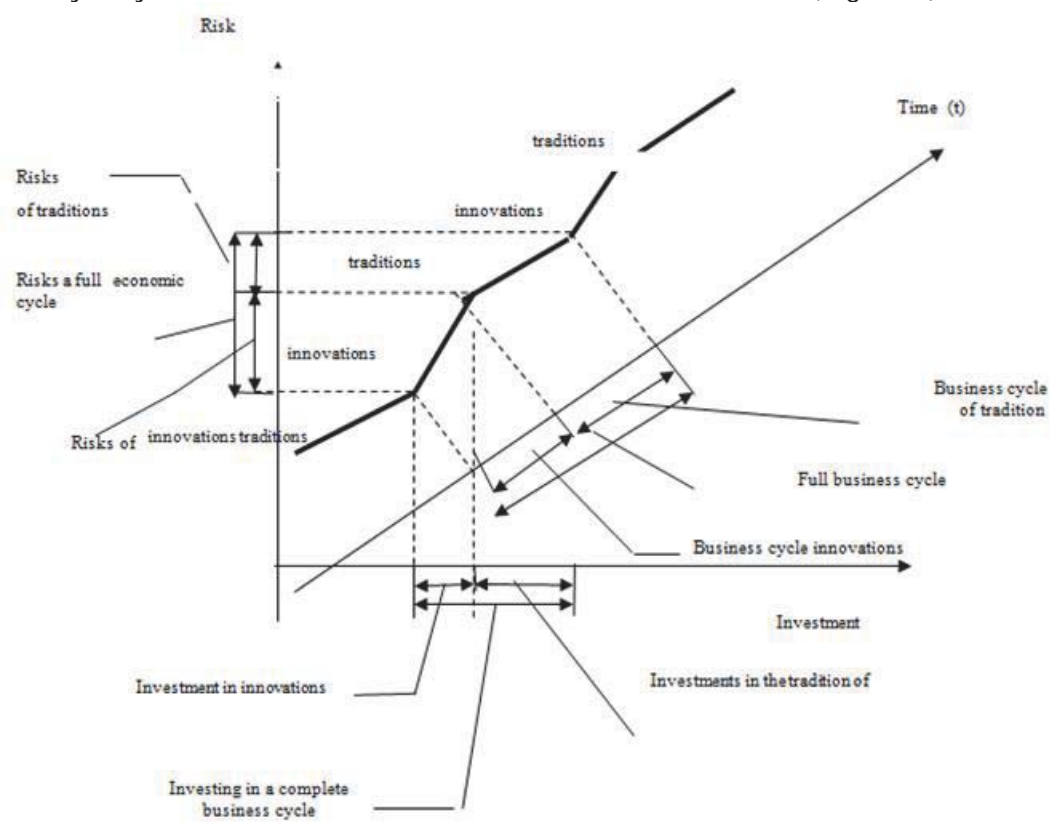

Figure 2. Cycles, patterns, investment and risk transformation of innovation into traditional relationships in economic systems. 
The third stage of the life cycle of innovation is its consumption or disposal. There is a "consolidation" of innovation as tradition, at the same time as it is detected and recognized as a rare usefulness - "peak" phase of growth innovation. This phase is preceded by a phase of slower growth of innovation, as the latter is characterized by rejection, lack of recognition of the existing structure of the innovation needs in connection with which there is a development of the new requirements for innovation.

The fourth stage - the update, which is a partial or complete replacement of innovation, as a result of the completion of a full business cycle downturn lifecycle innovation and the emergence of the next life cycle of innovation (see fig. 2).

It is well known that the transition from one quality to another requires the expenditure of resources (energy, time, finances, etc.). The translation process innovation (innovation) in the tradition also requires costs of various resources, the most important of which is the investment and time (see fig. 2).

Thus, innovation is a kind of activity that is associated with the transformation of ideas (the results of research and development or other scientific and technical achievement) to a new or improved product, introduced to the market in new or improved technological process used in practice.

Our investigation of the economic category of "Innovation" shows that the latter is directly dependent on these components of the financial market, as the capital market, investment, risk, financial resources, etc. Depending on the degree of interaction with these categories of innovation we can talk about the areas of implementation of innovations in financial markets. In the context of this research innovation implemented in the financial markets can be divided into two groups:

1. The introduction of new instruments in the financial markets. An example of such application will be called today have become a tradition derivatives - swaps, futures, forwards, and innovative financial products of the derivatives market - swaptions, credit derivatives, innovative leasing options etc.

2. The new (innovative) a combination of financial market instruments, allowing to design a variety of innovative financial products - and the stock exchange, derivatives and credit, financial innovation and the capital market, etc. - To increase the profitability of the enterprise, attracting investments, increase sales, insurance and innovative potential financial risks, financial and credit support innovation actors, etc. As an example of such a combination of innovative acts leasing, venture financing, forfaiting, franchising, special issue of securities, etc.

These products are the result of active innovation, characterized in economics as financial engineering.

\section{Financial Engineering}

The term "financial engineering" is now used in a variety of practical situations, scientists, researchers and practitioners, giving the same value of the concept of non-uniform. This is often due to the fact that financial engineering is a young and developing industry knowledge, as noted by U.S. researchers Vipul Bansal and John Marshall, any practitioner is inclined to consider their own experience as the most important, as the foundation on which to build and a new discipline.

Inaccuracies in the definition and use of the term "financial engineering" is not only complicate its place and role in economic science, but do not significantly promote the introduction of the domestic economic systems.

Study of the economic concept and essence of financial engineering in the first place to start with the term "financial engineering", which first appeared in the financial literature in the late 80's. the last century. By that time it strengthened the derivatives market, as well as a proliferation of different types of innovative financial products. Significant conversion of the derivatives market of the time are more affected U.S. financial markets, this explains the emergence and establishment of the U.S. market the concept of «financial engineering». Hence, a significant number of books, textbooks and research papers on the subject. The site www.amazon.com - the largest online bookstore published a list of the most popular books to date, relating to research in the field of financial engineering. The most significant research works are works of authors such as Frank J. Fabozzi (Editor), Janet M. Tavakoli, Jessica James, Nick Webber, Keith Cuthbertson, Dirk Nitsche, Yuh-Dauh Lyuu.

By analyzing data from the study, we note a practical focus to making concrete schemes and mechanisms for the application of certain financial innovation. In this case, special attention should be fundamental work Vipul Bansal and John Marshall, "Financial Engineering: A Complete Guide to Financial Innovation" and Lawrence Galica "Financial Engineering: Tools and methods of financial risk management." This is a comprehensive theoretical and practical work, which give an idea about the diversity occurring in the financial sector innovation.

Overview of the main discussion of the concepts of financial engineering in the Western theory and local know-how in this field indicates that the full talk about the Russian theory and practice of financial engineering is not necessary, research in the field of financial engineering are just beginning. Therefore, domestic researchers to this problem is more 
limited to the analysis and systematization of the existing foreign developments.

Thus, in their study Russian economist Yu Kapelinsky out two Western concepts:

1) financial engineering as the design of financial instruments and technologies for the management of a portfolio of securities Keperta Michel, co-president of the Swiss Association of Financial Engineers;

2) financial engineering as the creation, management and use of derivatives Fields Coudray, editor of financial magazine (Switzerland).

The above concept of limiting the activities of financial engineers to the sphere of securities as a whole (concept Michel Keperta), or limited solely to the derivative markets or, in a broader sense, the derivatives market (the concept of fields Coudray). According to the latest theory of the specificity of financial engineering in the derivatives market is associated with a focus on creating innovative characteristics of the well-known derivative instrument - futures (forward), option or swap, not the innovative product itself.

However, it should be noted that the very instruments of financial engineering in the derivatives market in many ways has the general characteristics and concepts of financial engineering in general. First of all, it concerns the process of modeling and a combination of innovative financial products. In this context, for the purposes of our study, we use a classic, in our view, the definition of financial engineering, the proposed J. Finnerty. Thus, financial engineering - the design, development and implementation of innovative financial instruments and processes, as well as creative new approaches to solving problems in the field of finance. The fundamental nature of this definition is that it succinctly and at the same time adequately describes the nature of the financial engineering as an economic category. It does not limit the scope of any financial engineering. In addition, its distinctive feature was the use of the word "creative" in relation to finance.

The rapid development of financial engineering was the result of a need to manage the ever-increasing innovation risks associated with the investment and innovation activities of economic subjects and the development of modern techniques and technologies that enable and facilitate the creation of innovative products aimed at solving financial problems.

As a reaction to the problem of liquidity have been developed and introduced some innovations to facilitate companies' access to cash, and others - to run temporarily idle cash. In Examples include money market funds, money market accounts, sweep accounts, electronic payment systems. A more complete list of the most specific demand in the market of financial innovation have received distribution was formed American researcher J. Finnerty in 1988. In academia, the list is known as the "List of Finnerty," which is often used for the analysis of visual displays examples of factors that have stimulated the emergence of financial instruments and solutions.

Other instruments have been developed to increase the liquidity of the existing tools, giving the market depth: sometimes it took the form of standardization previously non-standard tools, sometimes due to the restructuring of the financial instrument or activities that enhance credit worthiness.

But the main direction of development of financial engineering in the last twenty years has more to offset the various risks to prevent as much of the rational investors are more risk averse. Among the new effective tools and strategies for risk management for individual and institutional investors began to interest rate futures and options, stock index futures, options on stocks and stock indexes, foreign exchange derivatives, as well as a whole range of innovations exchange type (different variations swaps), various forms of strategy on the basis of duration and immunization, new methods of risk assessment, etc.

The key factor, and at the same time encourage the development of financial engineering is the concept of agency costs (agency costs), launched in 1976 by Michael Jensen and William Meckling. The idea of this concept reflects the fact that the managers of the company's own interests do not always coincide with the interests of the owners of the firm. Managers are able to enter into contracts, very profitable for itself, bringing in the "sacrifice" the interests of long-term growth of the company's own premium bonuses. This is the agency costs. Many innovations have 80's of the last century, for example repurchase using a lever or active use of junk bonds, have the ability to partially reduce such costs.

Financial and engineering activities are concentrated mainly in the financial services industry, and most of all it showed in the securities industry. The industry, on the one hand, financial engineering has helped to take shape, and the other - she was transformed them.

Speaking of the laws of development of financial innovation, we note the wave-like nature of their occurrence periodically have fundamental financial innovation - options, the potential of which is used for decades, which combined can create a variety of other, less significant innovation. After some time the fundamental innovations arise again, like we discussed before and shown in fig. 1 and 2. Thus, the development of financial innovation in general and in particular, is similar to the cyclical nature of the economy, characterized by a set of different wavelengths.

The influence of many factors predetermined the development of financial engineering. But if we talk more 
specifically, all the factors can be divided into external (environmental factors beyond the control of the economic operators, but providing them a direct impact) and internal (intra-factors).

The dominant external factors contributing to the emergence and development of financial engineering, include the destabilization of the world economy, the ever-increasing price volatility of globalization and the transformation of the industrial and financial markets, tax asymmetries, advances in science and technology.

On the other hand, considerable importance for financial engineering and have in-house factors - Need of liquidity, the ability to quickly and inexpensively to attract resources, aversion to risk management, agency costs, and many others.

One of the determining factors to the use of financial engineering techniques to market innovation is the insurance and risk mitigation.

The traditional approach to reduce various types of risks in theory and practice is to gain a penalty, guarantee, bank guarantee, mortgage, bills of exchange security and other remedies provided by applicable law. All the ways to ensure commitments are additional to the main obligation that they provide.

\section{Matrix Directions of the Innovative Features of Risk Engineering}

Given us examples of traditional approaches to reduce various types of risks in the theory and practice are more related to basic civil legal relations between the different actors (see Fig. 3, segment 1). However, most of them are absolutely not applicable to innovative financial products, by their nature. Since the nature of a last underlies financial engineering, then the methods and ways to reduce the risks involved in the market of innovative financial products need to look themselves in financial engineering instruments (see fig. 3, segment 2).

If the existing instruments do not meet the requirements set by the new task to reduce the risk, you need to create a new product based on the new conditions and the available tools (see fig. 3, segment 3), or solve the problem by getting a fundamentally new financial product as a result of achieving through financial engineering instruments synergistic innovation effect (see fig. 3, segment 4). The process of designing innovative financial products created to reduce risk through various instruments of financial engineering, and will be called the risk-engineering. Thus one of the main tasks of risk engineering is risk management, which, as already mentioned by us above, is one of the functions of the application of financial engineering.

Thus, in the most general definition of the purpose of our study under the risk-engineering refers to a set of methods of financial engineering aimed at eliminating or optimizing financial risks. Or, using the definition of financial engineering, we have given above, the risk-engineering, in our opinion, is a complex of measures, including the design, development and implementation of innovative financial products and processes, as well as creative new approaches to solving problems related to the management and reduction of risks arising from financial market subjects.

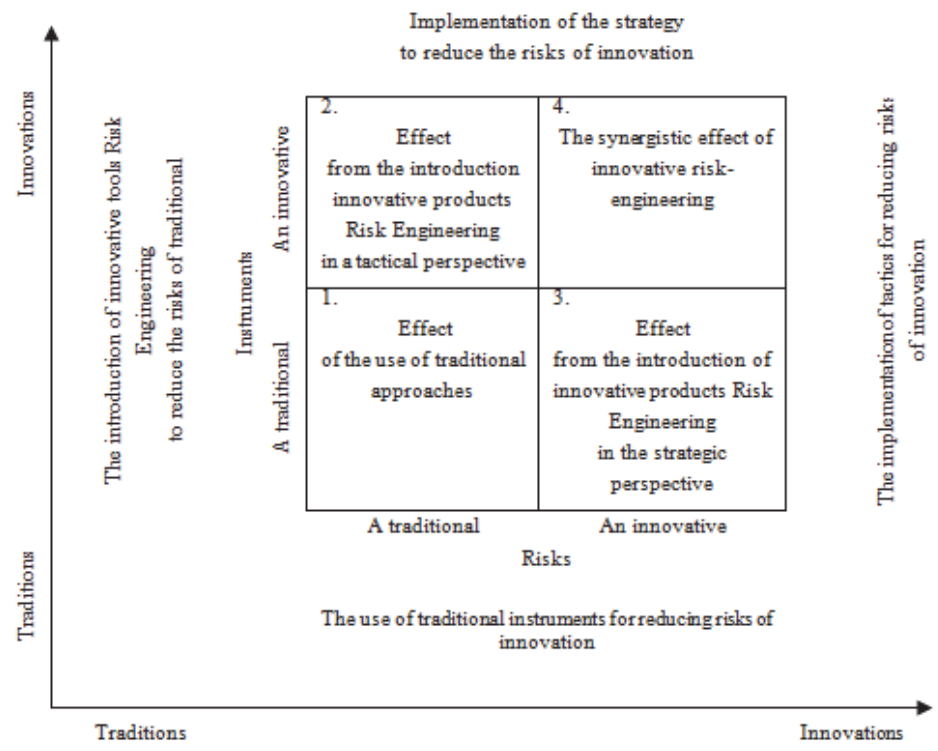

Figure 3. Matrix directions of the innovative features of risk engineering. 


\section{Conclusion}

Investigation of the application of risk-engineering reveals the following characteristics:

- The main objective of risk that affect the development of financial innovation is a credit, interest rate, market, an innovative risk and liquidity risk;

- The need for the application of risk-engineering as a set of techniques for insurance risk lies with both the demand side and the supply side of innovation of financial products;

- In the basis of the findings of such transactions are differences in predicting the behavior of the market, the different investment horizons, different tolerance to risk and subjective.

- Thus, the development of financial engineering today contribute to the factors that are common patterns of development of the financial market. All of the above factors favor us impetus to further development of financial engineering as a science, that is, practical scope of financial engineering intersects with the factors of its development. This kind of system, the elements of which are mutually influence each other: objective reasons require the creation of new financial products, which complicate economic relations, giving rise to all the new requirements that entail more sophisticated financial innovations.

\section{References}

Anisimova T.Yu. 2013. Analysis of Standards in Energy Management // Middle-East Journal of Scientific Research. Volume 13, Issue 5, Pages 654-657.

Bagautdinova N.G., Gafurov I.R., Kalenskaya N.V., Novenkova A.Z. 2012. The regional development strategy based on territorial marketing (the case of Russia) / World Applied Sciences Journal 18 (Special Issue of Economics), pp. 179-184.

Frank J. Fabozzi (Editor). Handbook of Financial Instruments. John Wiley \& Sons, Inc, 2002.

Janet M. Tavakoli. Credit Derivatives \& Synthetic Structures: A Guide to Instruments and Applications. John Wiley \& Sons, Inc, 2001.

Jessica James, Nick Webber. Interest Rate Modelling: Financial Engineering. John Wiley \& Sons Inc, 2000.

Keith Cuthbertson. Dirk Nitsche. Financial Engineering: Derivatives and Risk Management. John Wiley \& Sons, Inc, 2001.

Melnik A.N., Mustafina O.N. 2013. The Organization of Russian Power Market in Modern Conditions // Middle-East Journal of Scientific Research 13 (Socio-Economic Sciences and Humanities). P. 91-94.

Salih N. Neftci. Principles of Financial Engineering. Academic Press, 2008.

Safiullin L.N., Ismagilova G.N., Safiullin N.Z., Bagautdinova N.G. 2012. The development of welfare theory in conditions of changes in the quality of goods and services / World Applied Sciences Journal 18 (Special Issue of Economics), pp. 144-149.

Safiullin, M.R., Elstin, L.A., Shakirova, A.I. 2012. Evaluation of business and economic activity as a short-term forecasting tool // Herald of the Russian Academy of Sciences (4) , pp. 290-294.

Yuh-Dauh Lyuu. Financial Engineering and Computation: Principles, Mathematics, and Algorithms. Cambridge University Press. 1 edition (November 12, 2001).

Vipul Bansal and John Marshall, Financial Engineering. A Complete Guide to Financial Innovation. New York, Institute of Finance, 1992. XXIV $728 \mathrm{~S}$.

Safiullina A.M., Zhilina N.N., Shamsutdinova M .R. 2014. The main participants of innovation climate development (on the example of the Russian federation). Mediterranean Journal of Social Sciences.- Vol.5, No18, (2014)-pp. 197-201.

Fatkhiev, A.M., Bagautdinova, N.G., Novenkova, A.Z., Safiullina, A.M. 2014. The stages of the innovation process. Recent Trends in Social and Behaviour Sciences - Proceedings of the 2nd International Congress on Interdisciplinary Behavior and Social Sciences 2013, ICIBSoS 2013 pp. 315-318.

Shigabieva A.M., Safiullin L.N., Mazitov V.M., Saipullaev U.A. 2014. Some methodological foundation of an innovation theory. Life Science Journal 2014; 11(6s): 388 - 391. 